\title{
Laparoscopic Cholecystectomy After Endoscopic Trans-papillary Gallbladder Stenting for Acute Cholecystitis
}

\section{Fumihiro Kawano}

Juntendo University Graduate School of Medicine

Ryuji Yoshioka

Juntendo University Graduate School of Medicine

\section{Yu Gyoda}

Juntendo University Graduate School of Medicine

Hirofumi Ichida

Juntendo University Graduate School of Medicine

\section{Tomoya Mizuno}

Juntendo University Graduate School of Medicine

\section{Shigeto Ishii}

Juntendo University Graduate School of Medicine

\section{Toshio Fujisawa}

Juntendo University Graduate School of Medicine

Hiroshi Imamura

Juntendo University Graduate School of Medicine

Yoshihiro Mise

Juntendo University Graduate School of Medicine

Hiroyuki Isayama

Juntendo University Graduate School of Medicine

Akio Saiura ( $\square$ a-saiura@juntendo.ac.jp )

Cancer Institute Hospital https://orcid.org/0000-0001-5600-2847

\section{Research article}

Keywords: acute cholecystitis, gallbladder drainage, endoscopic trans-papillary gallbladder stenting, laparoscopic cholecystectomy, percutaneous transhepatic gallbladder drainage, elective surgery

Posted Date: December 16th, 2020

DOI: https://doi.org/10.21203/rs.3.rs-126084/v1 
License: (c) (i) This work is licensed under a Creative Commons Attribution 4.0 International License. Read Full License

Version of Record: A version of this preprint was published at BMC Surgery on April 7th, 2021. See the published version at https://doi.org/10.1186/s12893-021-01182-7. 


\section{Abstract}

Background: Percutaneous transhepatic gallbladder drainage (PTGBD) is indicated for patients with acute cholecystitis (AC) who are not indicated for urgent surgery, but external tubes reduce quality of life (QOL) while waiting for elective surgery. The objective of the present study was to investigate the feasibility of laparoscopic cholecystectomy after endoscopic trans-papillary gallbladder stenting (ETGBS) comparing with after PTGBD.

Methods: Intraoperative and postoperative outcomes of patients with ETGBS and PTGBD were retrospectively compared.

Results: Eighteen ETGBS and ten PTGBD patients were compared. Differences in the duration of ETGBS and PTGBD [median 209 minutes (range, 107-357) and median 161 minutes (range, 130-273), respectively, $P=0.10$ ], median blood loss [ETGBS 2 (range, 2-180 $\mathrm{ml}$ ) and PTGBD 24 (range, 2-100 ml), $P=0.89$ ], switch to laparotomy (ETGBS $11 \%$ and PTGBD 20\%, $P=0.52$ ), and median postoperative hospital stay [ETGBS 8 (range, 4-24 days) and ETGBS 8 (range 4-16 days), $P=0.99$ ]. Thickening of the cystic duct that occurred in $60 \%$ of the ETGBS patients and none of the PTGBD patients $(P=0.005)$ interfered with closure of the duct by clipping. No obstruction occurred in ETGBS patients.

Conclusion: ETGBS did not make laparoscopic cholecystectomy less feasible than after PTGBD.

\section{Introduction}

Gallbladder stones are present in nearly $90 \%$ of patients who experience acute cholecystitis (AC) $[1,2]$. Open surgery or laparoscopic cholecystectomy (LC), which has a shorter hospital stay, are standard treatments. Conservative treatment with antibiotics or gallbladder drainage may be chosen based on the condition of the patient or the severity of the AC. Percutaneous transhepatic gallbladder drainage (PTGBD), an effective and safe drainage procedure, has been used since the 1970s [3-5] but requires external tubes that decrease the quality of life (QOL) during the waiting period before elective surgery can be performed. As a drainage tool for AC, endoscopic trans-papillary gallbladder stenting (ETGBS) has been reported as an alternative to PTGBD.[6-8]. Some reports have focused on the short-term outcomes after LC with gallbladder drainage including both PTGBD and ETGBS, however no reports have addressed the feasibility of LC for AC after ETGBS comparing with LC after PTGBD [9-13]. This study evaluated the feasibility of laparoscopic cholecystectomy after ETGBS vs PTGBD.

\section{Materials And Methods}

\section{Study population}

A prospectively maintained database revealed that 240 patients underwent cholecystectomy between January 2017 and March 2019 in our institution. After excluding the patients who underwent open cholecystectomy, LC for chronic cholecystitis, or gallbladder polyp, 151 patients who underwent LC for AC 
were identified. Of these, 28 patients who underwent LC for AC after gallbladder drainage were included into the analyses (Fig. 1).

\section{Treatment}

AC was diagnosed by physical examination, laboratory findings, sonography, computed tomography, and evidence of wall thickening, inflammation, and fluid retention on magnetic resonance imaging. Although the Tokyo AC treatment guidelines recommend cholecystectomy soon after onset, we often encountered patients who were not candidates for urgent surgery because of severe cholecystitis, their comorbidities, or medical circumstances. [14]. Although we recognized LC as the standard of treatment for AC, urgent or semi-urgent LC for AC had not undergone basically during the study period based on the treatment criteria as previously reported. This attitude has been primarily due to the lack of various medical resources including medical staff. However, since April 2019, urgent LC has been indicated for the patients with AC who are tolerant for surgery. Prior to January 2017, PTGBD was the sole drainage method for acute cholecystitis in our institution. ETGBS was first adopted in January 2017.It has become the first choice for gallbladder drainage in our institution because we consider that an internalized tube of ETGBS has the advantage of maintaining the patient's quality of life during the waiting time prior to surgery when compared with the externalized tube of PTGBD. PTGBD was selected when endoscopy was not preferred because of technical difficulties, shortage of skilled labor, or the patient's condition. One patient in this series was treated by PTGBD at another hospital. Of the 151 study patients, $123(71 \%)$ were managed by conservative treatment. The remaining 28 patients (19\%) underwent gallbladder drainage, 18 by ETGBS, and 10 by PTGBD. Elective LC was basically performed $2-4$ months after the administration of antibiotics or from performing drainage. This was due to the insufficiency of medical resources and the available limitations.

\section{Gallbladder drainage}

Except for one PTGBD patient, gallbladder drainage was performed at our institution in the gastroenterology department. PTGBD was performed with ultrasound guidance, drainage was by a pigtail catheter, and angiography was performed under fluoroscopy to confirm that the catheter was correctly placed in the gallbladder. ETGBS was performed with sedation following sphincterotomy. Cannulation of the cystic duct was then conducted, followed by trans-papillary placement of a $7 \mathrm{Fr} 15-\mathrm{cm}$ double pigtail catheter in the gallbladder.

\section{Patient variables}

The baseline characteristics and laboratory data findings and intraoperative and postoperative outcomes of the elective LC in ETGBS and PTGBD patients were compared. The severity of AC was determined by the Tokyo guideline criteria [14]. Operation time, estimated blood loss, conversion to open surgery, availability of critical view of safety (CVS), cystic duct closure method, Clavien-Dindo complications, and postoperative hospital stay were the variables that were compared.

\section{Statistical analysis}


Binomial variables were compared using Pearson's $\chi 2$ test, and continuous variables were compared using the Mann-Whitney $U$ test. $P$-value of $<0.05$ was considered statistically significant. The statistical analysis was performed with JMP 11.2.0 (SAS Institute Inc., Cary, NC, USA).

\section{Results}

Patient status before drainage, severity of $A C$, and time from drainage to surgery are summarized in Table 1. Between-group differences were not significant excluded DIC $(P=0.049)$, but there was a tendency toward more severe AC in the PTGBD group $(P=0.08)$. 
Table 1

Characteristics of ETGBS and PTGBD patients before gallbladder drainage.

\begin{tabular}{|c|c|c|c|}
\hline Characteristic & ETGBS $(n=18)$ & PTGBD $(n=10)$ & $P$ \\
\hline Age & $71(52-88)$ & $77(48-86)$ & 0.23 \\
\hline Sex (male/female) & $15 / 3$ & $7 / 3$ & 0.41 \\
\hline \multicolumn{4}{|c|}{ Laboratory data before drainage } \\
\hline WBC (cells/mm³) & $14650(4700-36400)$ & $12500(7600-18300)$ & 0.29 \\
\hline Total bilirubin (mg/dl) & $1.7(0.54-23.44)$ & $0.87(0.44-3.9)$ & 0.30 \\
\hline Plt $\left(\times 10^{9}\right)$ & $18.8(12-30.9)$ & $29.3(6.4-31.2)$ & 0.77 \\
\hline Cre $(\mathrm{mg} / \mathrm{dl})$ & $0.70(0.33-1.33)$ & $0.87(0.61-10.33)$ & 0.12 \\
\hline AST (U/I) & $41(17-578)$ & $28(18-208)$ & 0.48 \\
\hline $\operatorname{ALT}(\mathrm{U} /)$ & $42(12-490)$ & $35(8-121)$ & 0.23 \\
\hline $\operatorname{ALP}(\mathrm{U} / \mathrm{I})$ & $215(159-2368)$ & $239(133-675)$ & 0.27 \\
\hline Alb (g/dl) & $3.2(2.7-5.1)$ & $3.3(2.9-4.6)$ & 0.51 \\
\hline $\mathrm{CRP}(\mathrm{mg} / \mathrm{dl})$ & $15.7(0.05-30.4)$ & $16.9(0.3-43.7)$ & 0.30 \\
\hline PT-INR & $1.11(0.99-1.43)$ & $1.02(0.89-1.78)$ & 0.72 \\
\hline DIC & & & \multirow[t]{3}{*}{0.049} \\
\hline Yes & 0 & 2 & \\
\hline No & 18 & 8 & \\
\hline \multicolumn{3}{|l|}{ Ascites } & \multirow[t]{3}{*}{ N.A. } \\
\hline Yes & 0 & 0 & \\
\hline No & 18 & 10 & \\
\hline \multicolumn{4}{|l|}{ Anticoagulant therapy } \\
\hline Yes & 4 & 3 & \multirow[t]{2}{*}{0.65} \\
\hline No & 14 & 7 & \\
\hline Time to operation (day) & $72(11-118)$ & $78(32-202)$ & 0.08 \\
\hline \multicolumn{4}{|l|}{$\mathrm{ASA}^{*}$} \\
\hline$\square$ & $5(28 \%)$ & $3(30 \%)$ & \multirow[t]{2}{*}{0.97} \\
\hline$\square$ & $8(44 \%)$ & $4(40 \%)$ & \\
\hline
\end{tabular}




\begin{tabular}{|llll|}
\hline Characteristic & ETGBS $(\mathbf{n}=18)$ & PTGBD $(\mathbf{n}=10)$ & $P$ \\
\hline$\square$ & $5(28 \%)$ & $3(30 \%)$ & 0.08 \\
\hline Grade** & & $7(70 \%)$ & \\
\hline I & $12(67 \%)$ & $1(10 \%)$ & $2(20 \%)$ \\
\hline III & $6(33 \%)$ & 0 & \\
\hline $\begin{array}{l}\text { *ASA, American Society of Anesthesiologists Physical Status Classification. }{ }^{* *} \text { Classified by the Tokyo } \\
\text { guidelines (17). Data are median (range) or number }(\%)\end{array}$ \\
\hline
\end{tabular}

The surgical outcomes of the drainage and non-drainage groups are shown in Table 2. There are significant differences between the drainage and non-drainage groups in the variables as follows; operation time, blood loss, conversion to open surgery, closure of cystic duct, and hospital stay, respectively. 
Table 2

Surgical results in No drainage and drainage patients.

\begin{tabular}{|c|c|c|c|}
\hline & No drainage $(n=123)$ & Drainage $(n=28)$ & $P$ \\
\hline Operation time(min) & $127(64-417)$ & $209(107-357)$ & $<0.0001$ \\
\hline Blood loss(ml)) & $8(1-195)$ & $21(2-180)$ & 0.0061 \\
\hline Conversion to open surgery & $5(4 \%)$ & $4(14 \%)$ & 0.0392 \\
\hline \multicolumn{4}{|l|}{ Confirmation of CVS } \\
\hline Yes & 117 & 20 & \\
\hline No & 6 & 8 & $<0.0001$ \\
\hline \multicolumn{4}{|l|}{ Closure of the cystic duct } \\
\hline Clipping & 117 & 16 & \\
\hline Ligation & 6 & 9 & $<0.0001$ \\
\hline \multicolumn{4}{|l|}{ ASA } \\
\hline 1 & 54 & 8 & \multirow[t]{3}{*}{0.118} \\
\hline 2 & 48 & 12 & \\
\hline 3 & 17 & 8 & \\
\hline \multicolumn{4}{|l|}{ Postoperative complication } \\
\hline \multicolumn{4}{|l|}{ Clavien-Dindo criteria } \\
\hline Grade I & 116 & 24 & \multirow[t]{3}{*}{0.403} \\
\hline Grade II & 4 & 4 & \\
\hline Grade IIla,b & 3 & 0 & \\
\hline Postoperative stay & $5(3-25)$ & $8(4-24)$ & 0.0063 \\
\hline \multicolumn{4}{|l|}{ CVS, critical view of safety } \\
\hline Data are median (range) or $r$ & Imber (\%) & & \\
\hline
\end{tabular}

Acute pancreatitis, perforation, bleeding, or other complications associated with either the ETGBS or the PTGBD procedures were not observed. Out of the 19, 18 ETGBS procedures were successful (95\%). One ETGBS patient was switched to PTGBD because cannulation of the cystic duct was not possible (Fig. 1).

Cholecystitis recurred in three patients in the PTGBD group (30\%) while waiting for surgery, but none of the patients in the ETGBS group experienced recurrent cholecystitis because of cystic duct occlusion. 
Intra- and postoperative factors in the ETGBS and the PTGBD group are summarized in Table 3 . The median operation times were 209 minutes (range, 107-357) for ETGBS and 161 minutes (range, 130$273)$ for PTGBD $(P=0.10)$. Switching to open surgery was needed in $11 \%$ in of ETGBS procedures and $20 \%$ of PTGBD procedures $(P=0.52)$. In each case, the reason for switching to open surgery conversion was severe inflammation. The attainment of CVS was impossible in 5 of the 18 ETGBS patients (28\%) and in 3 of 10 PTGBD patients $(30 \%)(P=0.90)$. Those patients were managed by a bail-out technique that involved fundus-first LC in four patients and conversion to laparotomy in four.

Table 3

Surgical results in ETGBS and PTGBD patients.

\begin{tabular}{|llll|}
\hline & ETGBS $(\mathbf{n}=18)$ & PTGBD $(\mathbf{n = 1 0})$ & $P$ \\
\hline Operation time(min) & $209(107-357)$ & $161(130-273)$ & 0.10 \\
\hline Blood loss $(\mathrm{ml})$ & $21(2-180)$ & $24(2-100)$ & 0.89 \\
\hline Confirmation of CVS & 13 & 7 & \\
\hline Yes & 5 & 3 & 0.9 \\
\hline No & $2(11 \%)$ & $2(20 \%)$ & 0.52 \\
\hline Conversion to open surgery & & & \\
\hline Closure of the cystic duct & & 8 & 0.005 \\
\hline Clipping & 7 & 0 & \\
\hline Ligation & 9 & & \\
\hline Postoperative complication & & 9 & \\
\hline Clavien-Dindo criteria & & 1 & 0.63 \\
\hline Grade I & 15 & 0 & \\
\hline Grade II & 3 & $8(4-16)$ & \\
\hline Grade III, IV, V & 0 & & \\
\hline Postoperative hospital stay & $8(4-24)$ & & \\
\hline CVS, critical view of safety & & & \\
\hline Data are median (range) or number $(\%)$ & & \\
\hline
\end{tabular}

The ETGBS tube was easily removed from the cystic duct by making an incision that was ligated with a double 5-mm M-L clip, but in 9 of the 18 cases (50\%), thickening of the cystic duct prevented the use of a clip and the duct was closed by ligation using with $2-0$ silk or an Endoloop ${ }^{\circledR}$ (PDS $₫$ Q) (ETHICON;NJ,USA). The cystic duct was closed with clips in all PTGBD patients $(P=0.005)$. There was no 
postoperative mortality and Clavien-Dindo Grade III or greater morbidities. There were no significant differences in the postoperative outcomes seen in the two study groups.

\section{Discussion}

After evaluating short-term outcomes, LC was found to be safe in patients with preoperative ETGBS. This is the first report of the evaluation of short-term outcomes focused on after each drainage method for AC of PTGBD vs ETGBS. The 2018 Tokyo guidelines recommend up-front cholecystectomy for mild or moderate $A C[14]$. However we occasionally encounter the situations in which urgent surgery for patients with severe AC could not be performed due to the patients' comorbidity or lack of medical resources. Gallbladder drainage is often necessary for such patients. PTGBD has been a standard treatment, but the external tube causes discomfort during the wait for surgery, and avoiding skin complications requires daily management. Other drainage methods are available. Although there have been reports on the safety of elective surgery after drainage[15], there have been no papers that focus on and compare the surgical outcomes of elective surgery after PTCD and ETGBS. This study evaluated the feasibility of laparoscopic cholecystectomy after ETGBS vs PTGBD

ETGBS is less likely than PTGBD to impair patient QOL during the wait for cholecystectomy, which is a clinically significant advantage. No patients with ETGBS experienced recurrent cholecystitis while waiting for surgery, but recurrent cholecystitis did occur in three of the ten with PTGBD (30\%). ETGBS can be performed by avoiding sphincterotomy even when patients have some risk of hemorrhage because of anticoagulant medications or those with disseminated intravascular coagulation (DIC). Bleeding complications are estimated to occur in $1.5-2.7 \%$ of PTGBD cases, with an increased bleeding risk in patients with a blood coagulation disorder $[16,17]$. Most patients with $A C$ require emergency drainage, and those taking anticoagulants, with severe inflammation accompanied by DIC or with ascites, do not qualify for PTGBD. ETGBS with trans-papillary cannulation may be indicated for such patients [17-19].

There are concerns of operative difficulty in patients with ETGBS because of inflammation around the cystic duct and cannulation of the drainage tube interfering with dissection in Calot's triangle. In this patient series, ETGBS did cause thickening of the cystic duct and inflammation of Calot's triangle (Fig. 2) that resulted in half of the patients requiring duct suturing because clip closure was not possible. Thickening of the cystic duct should be taken into consideration during surgery in patients with preoperative ETGBS. However, in this series, ETGBS did not increase the operative difficulty compared with PTGBD. The procedure duration, blood loss, and rates of conversion to open surgery were equivalent.

ETGBS cannot be performed patients in poor condition. Endoscopy of the biliary tract needs sedation that would not be tolerated by patients at risk of shock. In this study, two PTGBD patients had severe Tokyo grade III AC. There were no grade III patients in the ETGBS group. ETGBS is a complex procedure with a reported success rate of $77.3-89.5 \%[12,13,16-18,20]$. In this study, the success rate of ETGBS was 95\% (18 of 19 procedures), which is higher than in previous reports. One patient was switched to PTGBD from ETGBS because of incomplete cannulation of the cystic duct despite of the absence of stone 
incarceration. Procedure time of insertion of ETGBS is considered as longer than that of PTGBD. Although procedure time of ETGBS was not available due to the retrospective nature of the present study, it was reported to be around 35 minutes.[21]. Therefore, we consider that ETGBS is less burdensome than acute surgery for high risk patients. ETGBS-associated complications, including pancreatitis, liver dysfunction, biliary tract injury, and intestinal tract injury, have been reported in about $1.8 \%$ of procedures. That rate is similar to that reported for $\operatorname{ERCP}[17,19]$. No complications associated with ETGBS, including pancreatitis or perforation, occurred in this study. The limitations of this study include the small sample size, inclusion from a single institution, and its retrospective nature. However, to our knowledge, no studies have reported the outcomes of LC in patients with ETGBS compared those with PTGBD. Although this study has some novelty, it should be validated by prospective studies to address the actual feasibility of LC after ETGBS.

\section{Conclusion}

LC was performed successfully and safely after either ETGBS or PTGBD. ETGBS did not make laparoscopic cholecystectomy less feasible than after PTGBD.

\section{Abbreviations}

PTGBD: percutaneous transhepatic gallbladder drainage

AC: acute cholecystitis

ETGBS: endoscopic trans-papillary gallbladder stenting

QOL: quality of life

LC: Iaparoscopic cholecystectomy

DIC: disseminated intravascular coagulation

CVS: critical view of safety

ERCP: endoscopic retrograde cholangiopancreatography

\section{Declarations}

\section{Ethics approval andconsent to participate}

The study was approved by the Institutional Review Board of Juntendo University Graduate School of Medicine (no. 19-138) and performed following the ethical guidelines for clinical studies.

\section{Consent for publication}


Not applicable.

\section{Conflicts of interest/Competing interests}

Drs. Fumihiro Kawano, Ryuji Yoshioka, Yu Gyoda, Hirofumi Ichida, Tomoya Mizuno, Shigeto Ishii, Toshio Fujisawa, Hiroshi Imamura, Yoshihiro Mise, Hiroyuki Isayama, and Akio Saiura have nothing to disclose.

\section{Consent to participate}

Institutional Review Boards waived the need to sign an individual informed consent by each patient for this retrospective study. Informed consent was obtained from all individual participants included in the study.

\section{Availability of data and material}

The datasets used/and or analyzed in this study are available from the corresponding authors on reasonable request.

\section{Competing interests}

The authors declared no potential conflicts of interest with respect to the research, authorship, and/or publication of this article.

\section{Funding}

This manuscript has not received any funding.

\section{Contributions}

Research design: FK, RY, HI, AS. Acquisition of data: FK, RY, YG, HI, TM, HI, YM, SI, TF. Interpretation of data: FK, RY, YG, YM, SI, TF. All authors read and approved the final manuscript.

\section{Acknowledgments}

The authors would like to thank Enago (www.enago.jp) for English language review.

\section{References}

1. Glenn F (1976) Acute cholecystitis. Surg Gynecol Obstet 143:56-60

2. Browning, Horton JD (2003) Gallstone disease and its complications. Semin Gastrointest Dis 14:165177

3. Nakayama, Ikeda A, Okuda K (1978) Percutaneous transhepatic drainage of the biliary tract: technique and results in 104 cases. Gastroenterology 74:554-559 
4. Borzellino G, de Manzoni G, Ricci F, Castaldini G, Guglielmi A, Cordiano C (1999) Emergency cholecystostomy and subsequent cholecystectomy for acute gallstone cholecystitis in the elderly Acute cholecystitis in the elderly. Br J Surg 86:1521-1525.

5. Spira RM, Nissan A, Zamir O, Cohen T, Fields SI, Freund HR (2002) Percutaneous transhepatic cholecystostomy and delayed laparoscopic cholecystectomy in critically ill patients with acute calculus cholecystitis. Am J Surg 183:62-66.

6. Tamada K, Seki H, Sato K, Kano T, Sugiyama S, Ichiyama M (1991) Efficacy of endoscopic retrograde cholecystoendoprosthesis (ERCCE) for cholecystitis. Endoscopy 23:2-3

7. Feretis C, Apostolidis N, Mallas E, Manouras A, Papadimitriou J (1993) Endoscopic drainage of acute obstructive cholecystitis in patients with increased operative risk. Endoscopy 25:392-395.

8. Johlin FC, Neil GA (1993) Drainage of the gallbladder in patients with acute acalculous cholecystitis by transpapillary endoscopic cholecystotomy. Gastrointest Endosc 39:645-651.

9. Dumas, Caroli-Bosc FX, Demarquay JF, Zanaldi H, Hastier P, Conio M (1997) Acute inoperable cholecystitis treated by endoscopic naso-vesicular drainage. Study of 15 patients. Gastroentérologie clinique et biologique 21:854-858.

10. Feretis CB, Manouras AJ, Apostolidis NS, Golematis BC (1990) Endoscopic transpapillary drainage of gallbladder empyema. Gastrointest Endosc 36:523-525.

11. Huibregtse K, van Amerongen R, van Deventer SJ (1994) Drainage of the gallbladder in patients with acute acalculous cholecystitis by transpapillary endoscopic cholecystoxeransis. Gastrointest Endosc 40:523.

12. Berger, Topa L, Pap A (1994) Treatment of empyema of the gallbladder by endoscopic drainage. Orv Hetil 135:185-187.

13. Baron TH (2002) Endoscopic transpapillary gallbladder drainage for closure of calculous gallbladder perforation and cholecystoduodenal fistula. Gastrointest Endosc 56:753-755.

14. Okamoto K, Suzuki K, Takada T, Strasberg SM, Asbun HJ, Endo I, Iwashita Y, Hibi T, Pitt HA, Umezawa A, Asai K, Han HS, Hwang TL, Mori Y, Yoon YS, Huang WS, Belli G, Dervenis C, Yokoe M, Kiriyama S, Itoi T, Jagannath P, Garden OJ, Miura F, Nakamura M, Horiguchi A, Wakabayashi G, Cherqui D, de Santibanes E, Shikata S, Noguchi Y, Ukai T, Higuchi R, Wada K, Honda G, Supe AN, Yoshida M, Mayumi T, Gouma DJ, Deziel DJ, Liau KH, Chen MF, Shibao K, Liu KH, Su CH, Chan ACW, Yoon DS, Choi IS, Jonas E, Chen XP, Fan ST, Ker CG, Gimenez ME, Kitano S, Inomata M, Hirata K, Inui K, Sumiyama Y, Yamamoto M (2018) Tokyo Guidelines 2018: flowchart for the management of acute cholecystitis. J Hepatobiliary Pancreat Sci 25:55-72.

15. Doi S, Yasuda I, Mabuchi M, Iwata K, Ando N, Iwashita T, Uemura S, Okuno M, Mukai T, Adachi S, Taniguchi K (2018) Hybrid procedure combining endoscopic gallbladder lavage and internal drainage with elective cholecystectomy for acute cholecystitis: A prospective pilot study (The BLADE study). Dig Endosc 30:501-507.

16. Itoi T (2015) Endoscopic nasogallbladder tube or stent placement in acute cholecystitis: a preliminary prospective randomized trial in Japan (with videos). Gastrointestinal endoscopy 81:111- 
118

17. Toyota N, Takada T, Amano H, Yoshida M, Miura F, Wada K (2006) Endoscopic naso-gallbladder drainage in the treatment of acute cholecystitis: alleviates inflammation and fixes operator's aim during early laparoscopic cholecystectomy. J Hepatobiliary Pancreat Surg 13:80-85.

18. Mohan BP (2019) Endoscopic ultrasound-guided gallbladder drainage, transpapillary drainage, or percutaneous drainage in high risk acute cholecystitis patients: a systematic review and comparative meta-analysis. Endoscopy

19. Salameh H (2019) Endoscopic retrograde cholangiopancreatography and endoscopic ultrasoundguided gallbladder drainage. Gastrointest Endosc Clinics North America 29:293-310.

20. Corral JE, Das A, Krner PT, Gomez V, Wallace MB (2019) Cost effectiveness of endoscopic gallbladder drainage to treat acute cholecystitis in poor surgical candidates. Surg Endosc 33:35673577.

21. Yang MJ, Yoo BM, Kim JH, Hwang JC, Baek NH, Kim SS, Lim SG, Kim JH, Shin SJ, Cheong JY, Lee KM, Lee KJ, Kim WH, Cho SW (2016) Endoscopic naso-gallbladder drainage versus gallbladder stenting before cholecystectomy in patients with acute cholecystitis and a high suspicion of choledocholithiasis: a prospective randomised preliminary study. Scand J Gastroenterol 51:472-478.

\section{Figures}


[Figure 1]

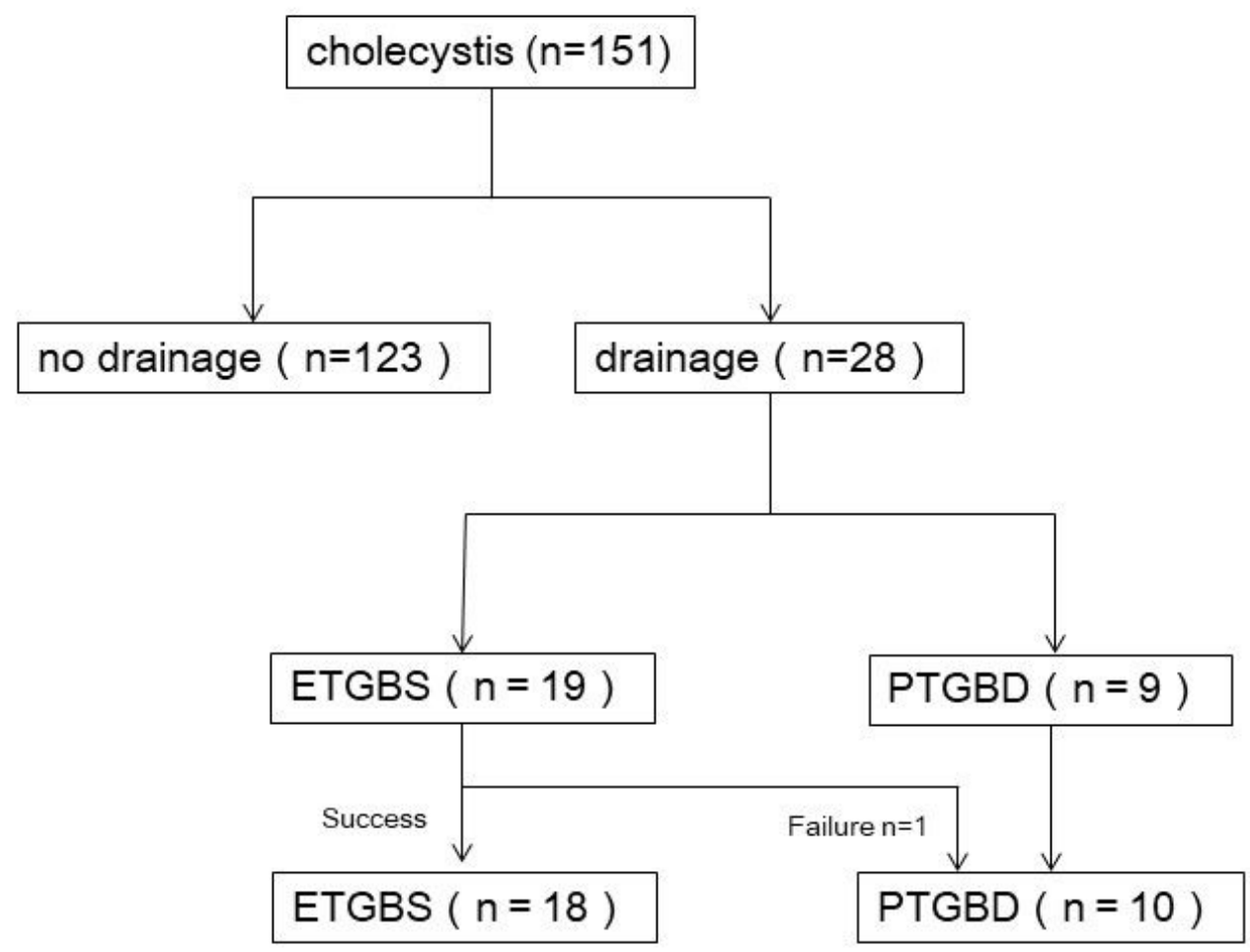

Figure 1

Patient flow diagram. 
[Figure 1]

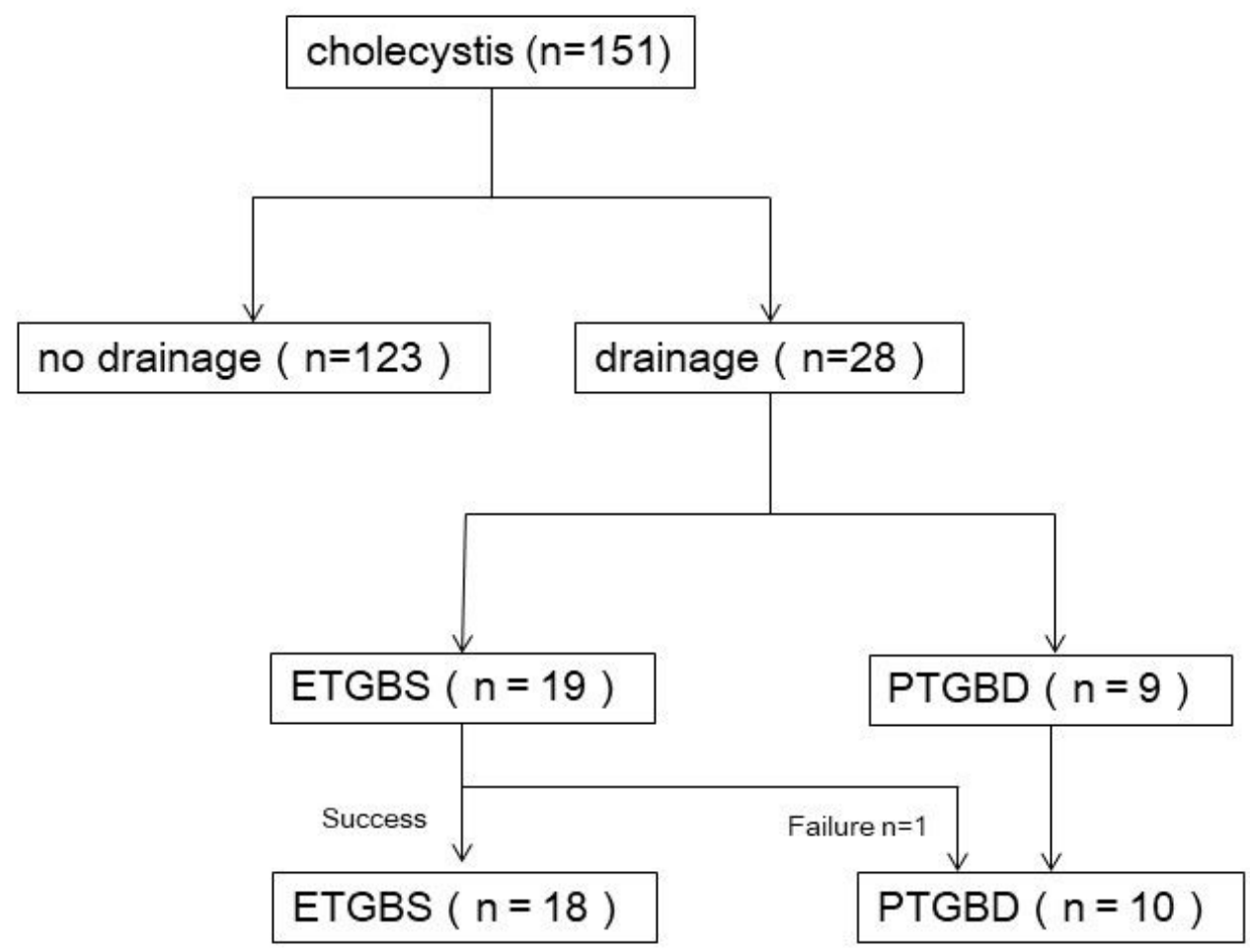

Figure 1

Patient flow diagram. 


\section{IFigure 2】}

A

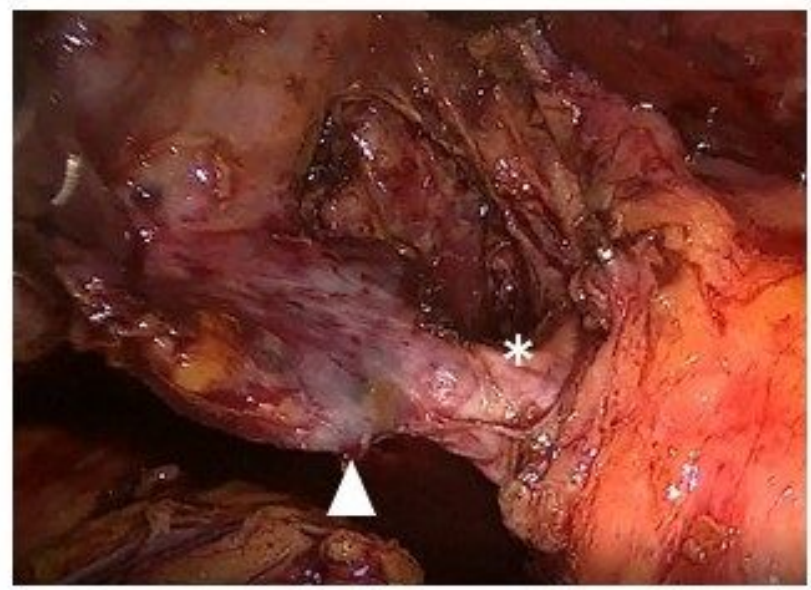

B

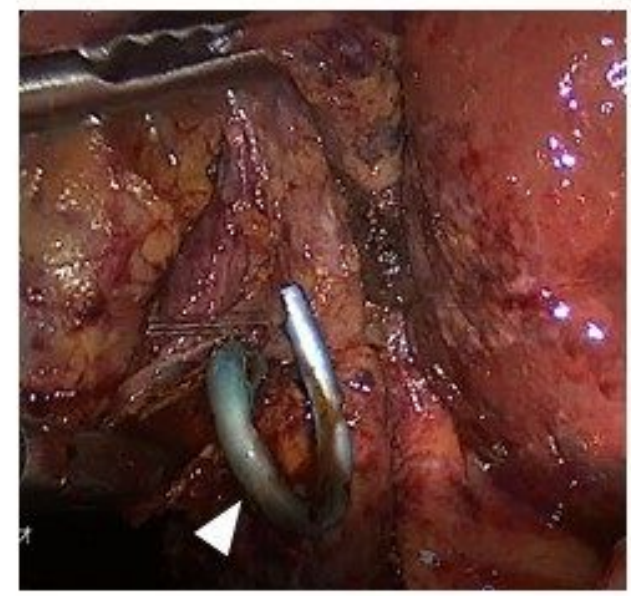

\section{Figure 2}

Representative intraoperative images of patients with preoperative ETGBS. (A) Critical view of safety and cystic duct thickening $\left(^{*}\right)$. The arrowhead shows the ETGBS from the outside of the duct. (B) The ETGBS tube (arrowhead) was removed via the incision of the cystic duct. 


\section{【Figure 2】}

A

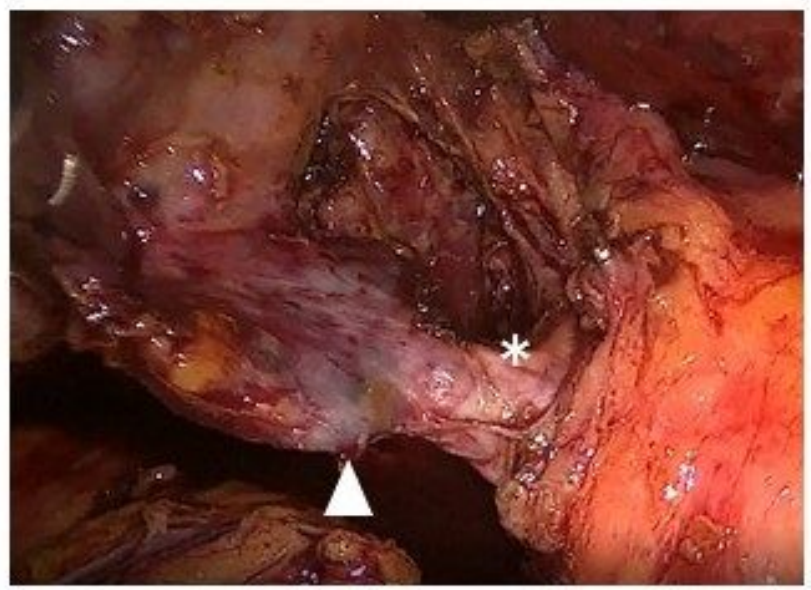

B

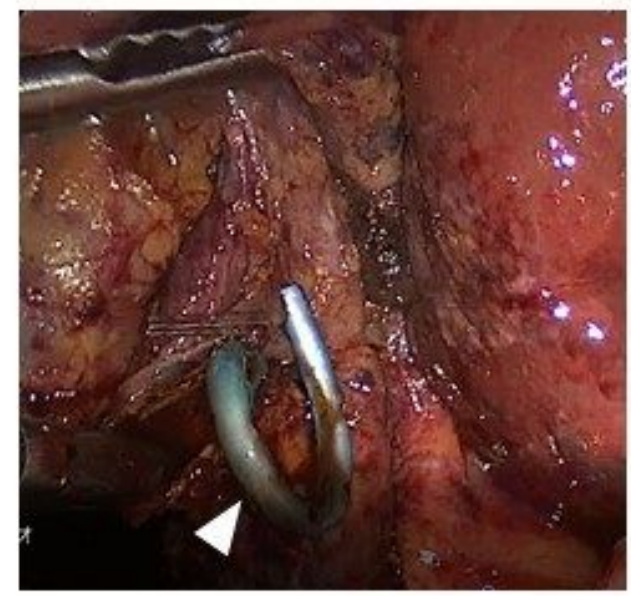

\section{Figure 2}

Representative intraoperative images of patients with preoperative ETGBS. (A) Critical view of safety and cystic duct thickening $\left(^{*}\right)$. The arrowhead shows the ETGBS from the outside of the duct. (B) The ETGBS tube (arrowhead) was removed via the incision of the cystic duct. 